\title{
Impact of revascularization and factors associated with limb salvage in patients with diabetic foot
}

Carlos A. Hinojosa, Estefanía Boyer-Duck, Javier E. Anaya-Ayala, Ana E. Núñez-Salgado, Hugo Laparra-Escareno and René Lizola

Instituto Nacional de Ciencias Médicas y Nutrición Salvador Zubirán, Surgery Head Office, Angiology and Vascular Surgery Section, Ciudad de México, Mexico

\begin{abstract}
Introduction: Diabetic foot is a common cause of hospitalization. Objective: To examine the impact of revascularization on lower limb salvage. Method: Retrospective study of diabetic patients with foot ulcers. The extent of tissue loss was assessed according to the PEDIS and Wagner classifications, and revascularization indications and techniques were evaluated. Factors involved with major amputation and limb salvage were assessed with Fisher's and chi-square tests. Results: A total of 307 patients with a mean age of 61 years were included in the study; 198 (64\%) were males; 53 (17\%) underwent limb revascularization, $26(8 \%)$ with endovascular techniques and 27 (9\%) with open surgery; 27 belonged to PEDIS grade $3(51 \%)$ and $21(41 \%)$ to Wagner's classification grade 4; $52 \%$ of revascularized patients required major amputation versus $25 \%$ of those without revascularization. Comorbidities, demographic variables, complications and mortality showed no differences when patients who required major amputation were compared with those who didn't. Conclusion: Despite revascularization, the limb was preserved in less than $50 \%$ of patients. Early referral to vascular surgery and appropriate patient-selection criteria might increase limb salvage.
\end{abstract}

KEY WORDS: Diabetic foot. Limb salvage. Amputation.

\section{Introduction}

Lower-limb ulcerous lesions in patients with diabetes mellitus are a complication with important consequences. ${ }^{1}$ The risk for developing an ulcer at least once in life has been estimated to be approximately $25 \%$ in this group of patients. ${ }^{\text {Since these lesions }}$ are associated with increased risk of amputation of the affected extremity, primary therapeutic goal is limb preservation. ${ }^{2}$ From the economic point of view, up to one third of treatment cost in diabetic patients is estimated to be attributable to the management of foot ulcers. ${ }^{3}$ These lesions do develop in approximately one fourth of patients with diabetes, and in half of them, serious tissue infection can occur that requires hospitalization, use of intravenous antibiotics and aggressive surgical treatment; in spite of optimal treatment, up to a fifth part of these patients end up requiring major amputation. ${ }^{4}$ Once a diabetic foot-associated major amputation has occurred, mortality exceeds the rates reported for some types of cancer; it ranges from 39 to $80 \%$ within the first 5 years. ${ }^{5,6}$ To reduce the number of amputations, coordination of the health system and a multidisciplinary approach are essential. 7,8

The development of foot ulcers is attributable to numerous interacting factors, with peripheral neuropathy and peripheral artery disease standing out. ${ }^{7}$ The latter is a factor that has a considerable impact, since a circulatory disorder can be demonstrated in up to $50 \%$ of patients. ${ }^{9}$ Limb revascularization, either by open surgery (which includes direct arterial reconstruction or bypass) or endovascular procedures, is the invasive treatment available to improve symptoms. ${ }^{10}$ Among
Date of reception: 19-07-2016

Date of acceptance: 30-12-2016

DOI://dx.doi.org/10.24875/GMM.M18000129
Gac Med Mex. 2018;154:146-152

Contents available at PubMed www.gacetamedicademexico.com 
diabetic and non-diabetic patients with peripheral artery disease, clinical researchers have focused their efforts on understanding the impact of endovascular revascularization. A reduction in the rate of amputations and open surgery-associated complications has certainly been demonstrated, although some empirical analyses have not reported significant changes in the need for major amputations, in spite of less invasive revascularization techniques. ${ }^{11}$

There are only few investigations in Mexico that have approached the direct impact of revascularization and the ulcer healing rate as a specific result of intervention in patients with diabetic foot. ${ }^{12}$ The purpose of this study was to assess the impact of open and endovascular revascularization in diabetic patients with ulcerous foot lesions treated at Instituto Nacional de Ciencias Médicas y Nutrición Salvador Zubirán and to determine the factors that influenced on selection and limb salvage in this population until before 2012 in this institution.

\section{Method}

Longitudinal, descriptive study and descriptive analysis comprising the period from 1997 to 2012, where 307 patients with confirmed diagnosis of type 1 or 2 diabetes who developed ulcerous foot lesions were included.

According to the World Health Organization, "diabetic foot" was defined as ulceration, infection and destruction of lower limb tissues associated with neurological alterations and different degrees of peripheral vascular disease. ${ }^{13}$ The Wagner and PEDIS classifications-which include variables such as level of perfusion, extension, depth, tissue loss, infection and diabetic neuropathy- ${ }^{14}$ were used to select patients who required any revascularization procedure.

Information was collected on demographic variables (gender, age, socioeconomic status), comorbidities, laboratory tests (glycated hemoglobin, cholesterol and triglyceride levels), ulcer characteristics (number, location and depth), as well as presence of osteomyelitis.

Interventions aimed at reestablishing or improving circulation included open surgeries (femoropopliteal bypass, femoral endarterectomy, thrombectomy) and endovascular interventions (angioplasty and vascular endoprosthesis placement); complications and re-interventions were analyzed. The outcome was determined based on the need for major amputation (supracondylar or infracondylar). "Limb salvage" was defined as the situation where complete healing of the
Table 1. Distribution by gender of patients who preserved the extremity or who underwent major amputation

\begin{tabular}{|c|c|c|c|c|}
\hline & Limb salvage* (\%) & Major amputation (\%) & Total (n) & $\mathbf{p}$ \\
\hline \multirow[t]{2}{*}{ Gender } & Females: 62 & Females: 38 & 198 & \\
\hline & Males: 63 & Males: 37 & 109 & 0.80 \\
\hline \multicolumn{3}{|c|}{${ }^{*}$ Includes minor amputation } & $\frac{(\sigma)}{\frac{E}{6}}$ & \\
\hline
\end{tabular}

ulcer or the need for minor or more conservative amputation was achieved (toe, transmetatarsal), which enabled rapid recovery and rehabilitation in a 3-month period. Statistical analysis was descriptive, clinical variables and comorbidities were expressed as percentiles, means, medians and standard deviation. Factors involved with the outcome (major amputation versus limb salvage) were analyzed with Fisher and chi-square tests, with the purpose to find group differences. The tests were carried out with the statistical program Stata, version 14.0.

\section{Results}

A total of 307 diabetic patients with a mean age of $61 \pm 14$ years, who were assessed at the Instituto Nacional de Ciencias Médicas y Nutrición Salvador Zubirán Wound Clinic and diagnosed with diabetic foot were included; 198 (64\%) belonged to the male gender and 109 (36\%) were females (Table 1).

A total of 297 patients had been diagnosed with type 2 diabetes (97\%) and 10 with type 1 diabetes (3\%); 226 patients (74\%) had systemic arterial hypertension, 200 (65\%) had dyslipidemias, 114 (37\%) had a known diagnosis of peripheral artery disease and $54(18 \%)$ had a history of acute myocardial infarction; $53(17 \%)$ underwent revascularization intervention, 26 were treated with endovascular techniques (angioplasty or vascular endoprosthesis placement) and 27 with open revascularization. The decision to intervene was based on PEDIS and Wagner classifications, with the purpose to avoid major amputation. Twenty-seven patients $(51 \%)$ were classified in PEDIS grade 3 and $21(41 \%)$ in Wagner grade 4 (Fig. 1); $52 \%$ of revascularized patients required major amputation, in comparison with $25 \%$ of non-revascularized subjects,

Tables 2 and 3 and figure 2 include the demographic variables and comorbidities in revascularized and non-revascularized patients, which showed no differences when patients who required major amputation were compared with revascularized patients who required conservative amputation. In non-revascularized patients, peripheral artery diagnosis $(p=0.001)$ and history of 

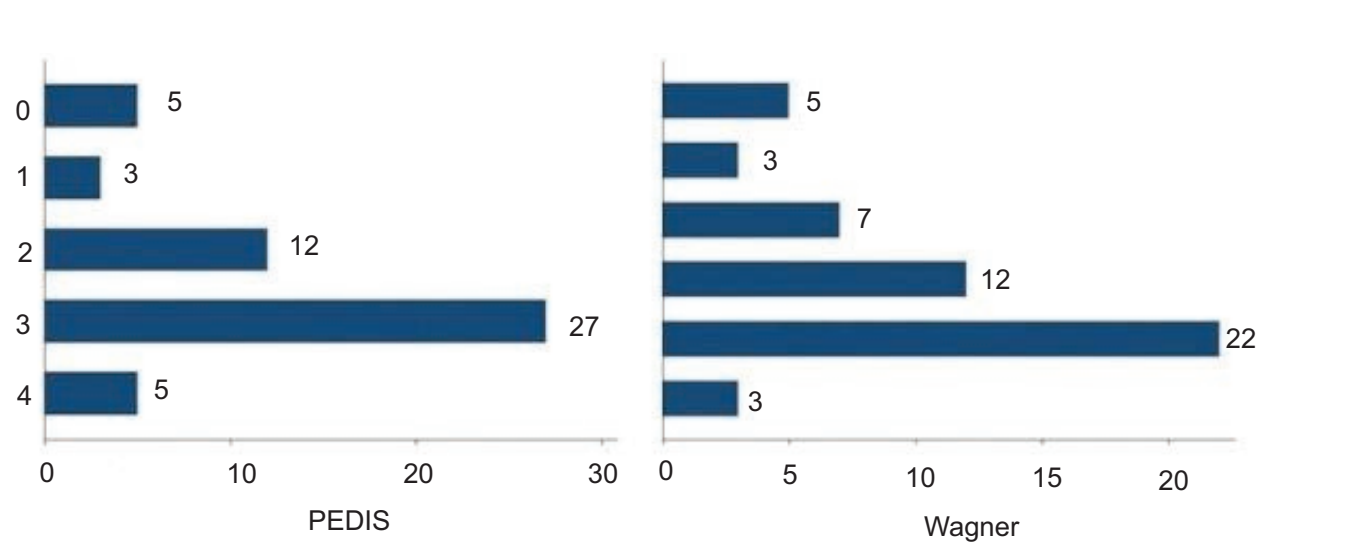

Figure 1. Distribution of the numbers of patients undergoing revascularization according to PEDIS and Wagner classifications.

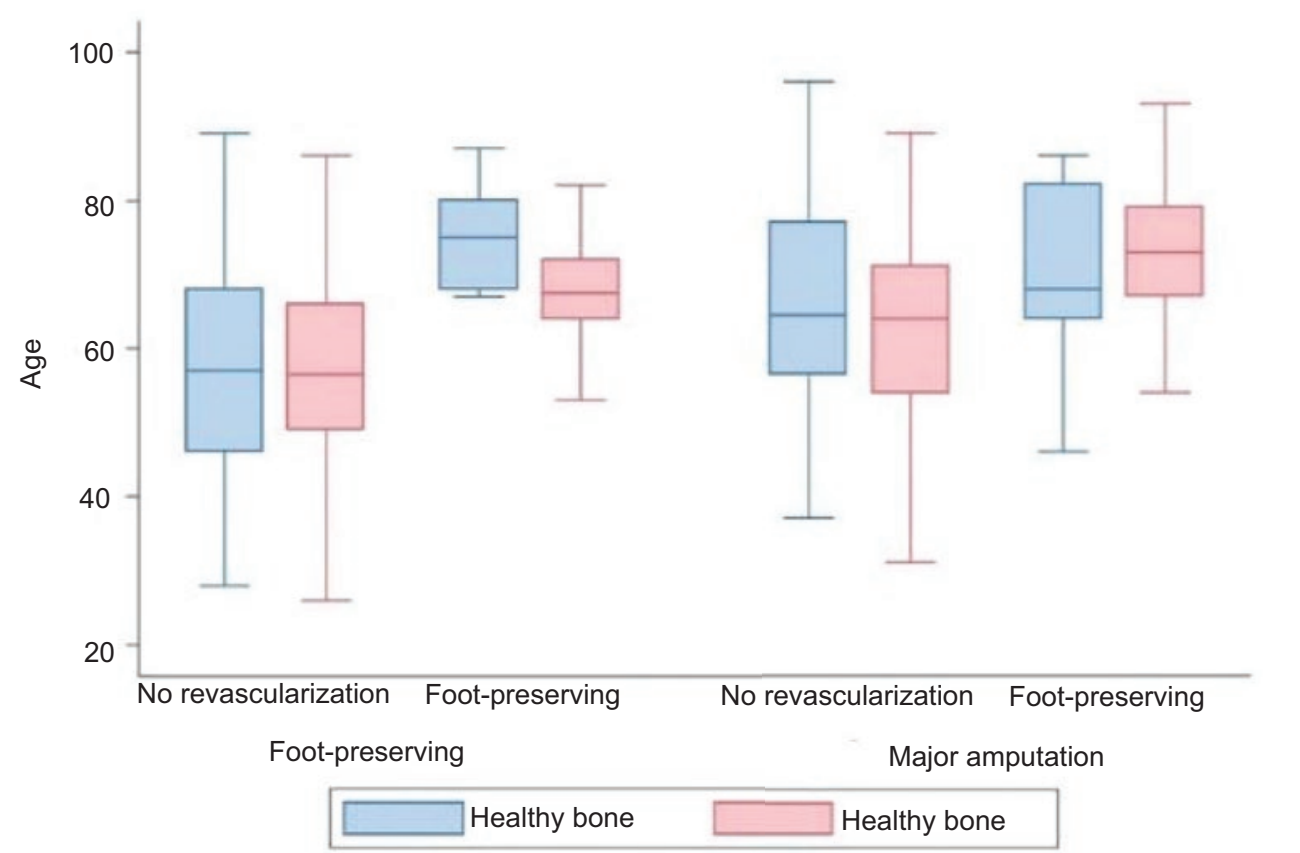

Figure 2. Distribution by age of patients who underwent revascularization or not, presence of osteomyelitis and outcome (foot-preserving amputation, limb salvage or major amputation).

acute myocardial infarction $(p=0.003)$ influenced on the need for major amputation to be carried out.

On the other hand, in the group of patients who did not undergo revascularization, platelet antiaggregants were observed to contribute to limb salvage $(p=0.001)$. Mean age of patients who required major amputation was 65 years in comparison with 58 years in those who didn't ( $p=0.0001)$; in non-revascularized patients who required major amputation, mean age was 63 years, in comparison with 71 in those who underwent revascularization $(p=0.006)$. There were no differences in mortality or major complications in revascularized patients who preserved the extremity or required major amputation. Figure 2 depicts age distribution of patients who underwent revascularization or not, the presence of osteomyelitis and the outcome (conservative foot amputation, limb salvage or major amputation).

Major amputations occurred more often patients with PEDIS classification grade 3 and Wagner grade 4 . No trend was observed towards a higher number of these amputations, regardless of the revascularization technique. Figures 3 and 4 show the distribution of patients with major amputation who did not undergo revascularization and of those who underwent endovascular or open revascularization, according to PEDIS and Wagner classifications.

\section{Discussion}

"Critical limb ischemia" is a concept that was introduced in 1982; ever since, its different 
Table 2. Demographic variables and comorbidities of patients undergoing revascularization

\begin{tabular}{|c|c|c|c|c|c|}
\hline & Limb salvage (\%) & Major amputation (\%) & Total (\%) & & $p$ \\
\hline Gender & $\begin{array}{l}\text { F: } 48 \\
\text { M: } 50\end{array}$ & $\begin{array}{l}F: 52 \\
M: 50\end{array}$ & $\begin{array}{l}F: 33 \\
M: 20\end{array}$ & $\frac{\infty}{\circ}$ & 1.00 \\
\hline $\mathrm{SAH}$ & 51 & 49 & 41 & $\stackrel{1}{2}$ & 0.50 \\
\hline Obesity & 67 & 33 & 3 & है & 1.00 \\
\hline Dyslipidemia & 44 & 56 & 32 & $\therefore$ & 0.40 \\
\hline AMI & 31 & 69 & 16 & & 0.13 \\
\hline $\mathrm{CHF}$ & 71 & 29 & 7 & $\ddot{\amalg}$ & 0.25 \\
\hline PAD & 50 & 50 & 42 & $\underline{\bar{n}}$ & 1.00 \\
\hline Stroke & 63 & 38 & 8 & อ & 0.46 \\
\hline Hemodialysis & 50 & 50 & 4 & $\subsetneq$ & 1.00 \\
\hline COPD & 50 & 50 & 2 & $\frac{0}{c}$ & 1.00 \\
\hline Statins & 56 & 44 & 18 & $\bar{n}$ & 0.56 \\
\hline Antiaggregant & 49 & 51 & 35 & $\frac{5}{4}$ & 1.00 \\
\hline Anticoagulant & 50 & 50 & 6 & $\frac{\varsigma}{\varrho}$ & 1.00 \\
\hline Osteomyelitis & 50 & 50 & 28 & $\frac{7}{5}$ & 0.78 \\
\hline Tobacco & 45 & 55 & 29 & ১ & 0.57 \\
\hline
\end{tabular}

F, female; $\mathrm{M}$, male; $\mathrm{SAH}$, systemic arterial hypertension; $\mathrm{AMI}$, acute myocardial infarction; $\mathrm{CHF}$, congestive heart failure; $\mathrm{PAD}$, peripheral artery disease; COPD, chronic obstructivepulmonary disease.
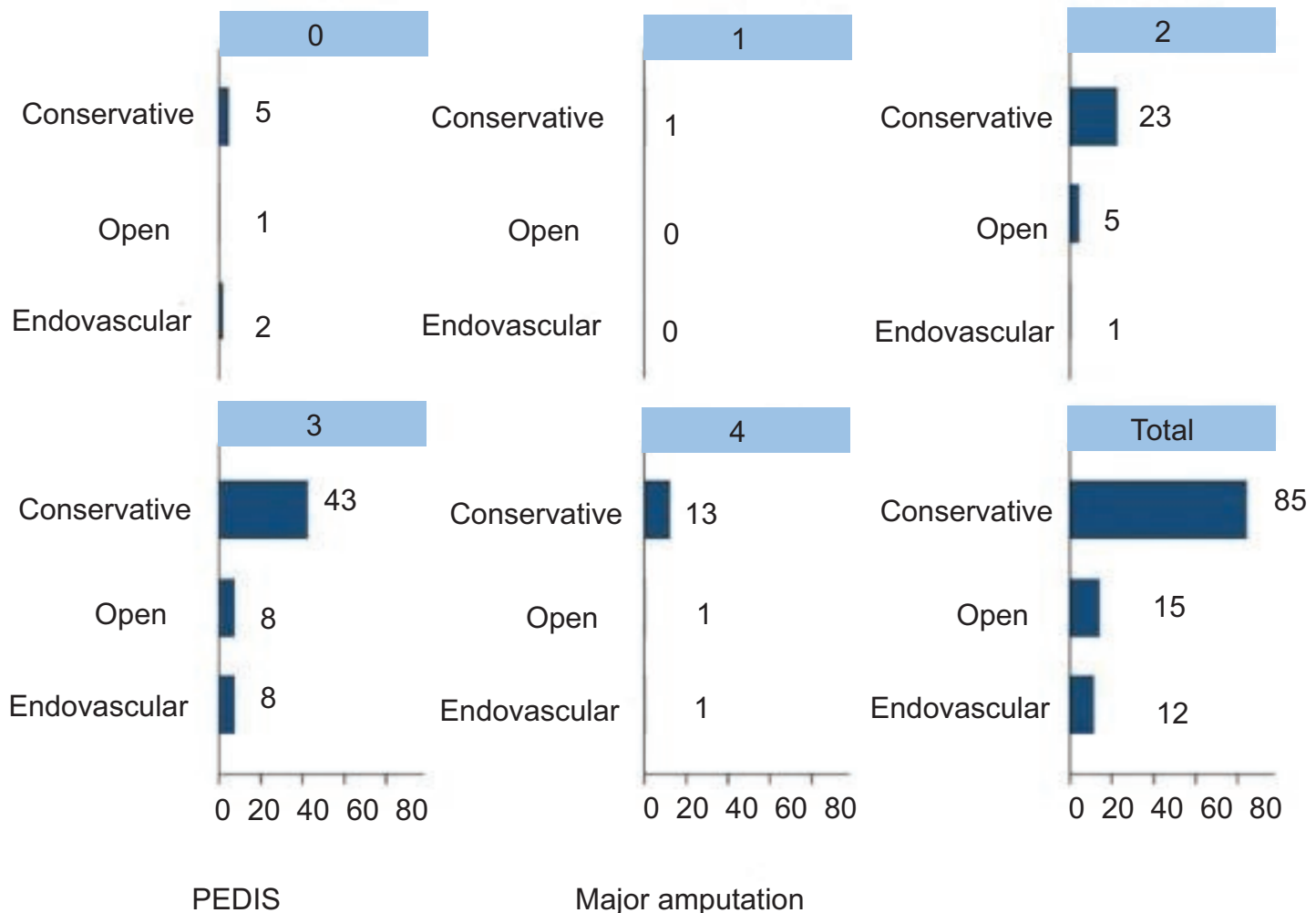

PEDIS

Major amputation

Figure 3. Distribution of patients with major amputation who did not undergo revascularization and of those who underwent revascularization (endovascular or open) according to PEDIS classification. 
Gaceta Médica de México. 2018;154
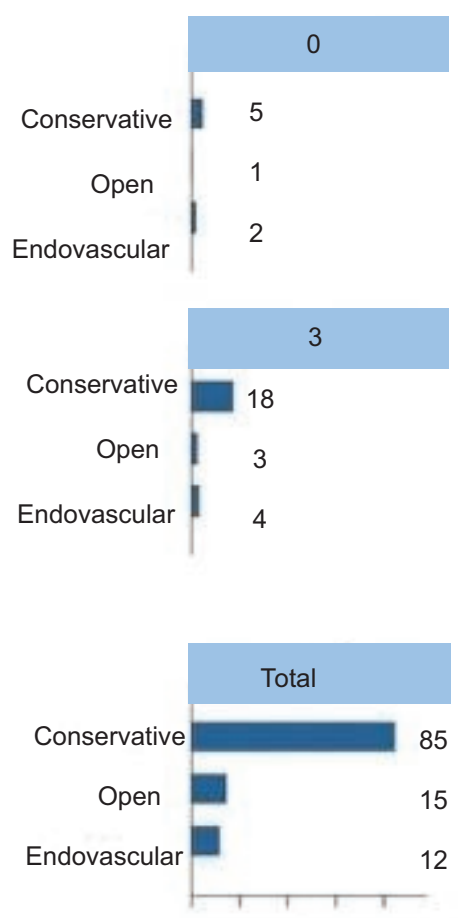

020406080
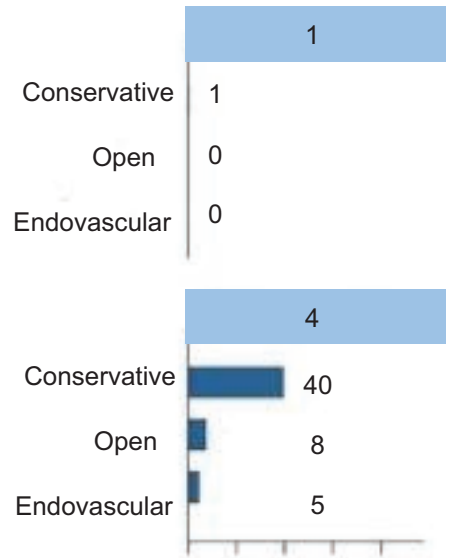

020406080

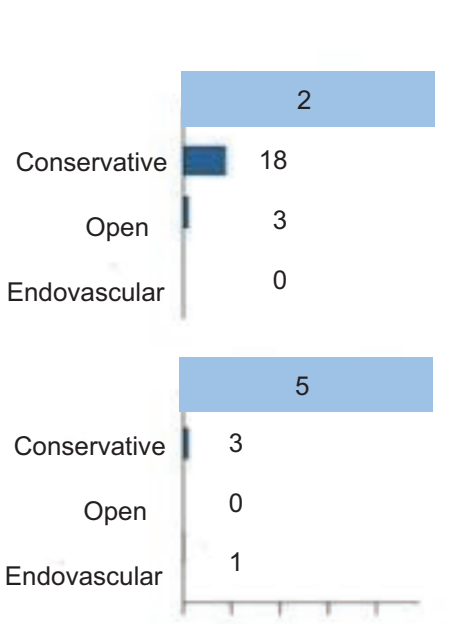

020406080

PEDIS

Major amputation

Figure 4. Distribution of patients with major amputation who did not undergo revascularization and of those who underwent revascularization (endovascular or open) according to the Wagner classification.

Table 3. Demographic variables and comorbidities of patients not undergoing revascularization

\begin{tabular}{|c|c|c|c|c|c|}
\hline & Limb salvage (\%) & Major amputation (\%) & Total (\%) & 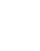 & $p$ \\
\hline Gender & $\begin{array}{l}F: 64 \\
M: 66\end{array}$ & $\begin{array}{l}\text { F: } 36 \\
\text { M: } 34\end{array}$ & $\begin{array}{c}\text { F: } 89 \\
\text { M: } 165\end{array}$ & . & 0.78 \\
\hline SAH & 65 & 35 & 185 & & 1.00 \\
\hline Obesity & 73 & 27 & 52 & gi & 0.193 \\
\hline Dyslipidemia & 65 & 35 & 168 & $\frac{3}{0}$ & 0.89 \\
\hline AMI & 42 & 58 & 38 & $\frac{\partial}{d}$ & 0.003 \\
\hline $\mathrm{CHF}$ & 58 & 42 & 24 & $\stackrel{1}{2}$ & 0.50 \\
\hline PAD & 44 & 56 & 72 & & 0.001 \\
\hline Stroke & 65 & 35 & 26 & 둥 & 1.00 \\
\hline Hemodialysis & 55 & 45 & 31 & $\underline{\underline{0}}$ & 0.25 \\
\hline COPD & 33 & 67 & 3 & & 0.28 \\
\hline Statins & 57 & 43 & 84 & $\stackrel{n}{c}$ & 0.70 \\
\hline Antiaggregant & 55 & 45 & 130 & $\circ$ & 0.001 \\
\hline Anticoagulant & 58 & 43 & 7 & $\stackrel{\frac{\pi}{2}}{2}$ & 0.69 \\
\hline Osteomyelitis & 62 & 38 & 129 & $z$ & 0.28 \\
\hline Tobacco & 68 & 32 & 124 & & 0.50 \\
\hline
\end{tabular}


classifications have set the tone in clinical decision for revascularization procedures to be carried out. ${ }^{15}$ Originally, it defined patients without diabetes at higher risk of losing a limb due to chronic ischemia; the authors who coined the concept agreed that patients with diabetes had a more complex clinical expression that included neuropathy, sepsis and ischemia. In the ensuing years, the use of "critical ischemia" was inappropriately attributed to a broader spectrum of clinical expressions, without taking into consideration whether patients were diabetic or non-diabetic.

On the other hand, PEDIS and Wagner classifications have been used to classify the degree of tissue destruction and infection in diabetic patients with ulcerous lesions; however, these systems have failed to provide sufficient details relative to the state of perfusion and are systems that evaluate ulcers, without addressing the presence of gangrene, which is known to increase the degree of amputation in comparison with an ulcer. ${ }^{16}$ Although the Wagner ${ }^{17}$ classification includes gangrene, it doesn't clearly differentiate if the ischemic state is the result of infection or gangrene, in addition to not characterizing the degree of infection, ischemia and lesion extent. In 2014, the Society for Vascular Surgery, in the United States of America, introduced the Wound, Ischemia and Foot Infection classification, with the purpose to more appropriately select patients requiring revascularization and to increase the knowledge of patients who might benefit from these interventions. ${ }^{18}$ In recent years, authors such as Zhan ${ }^{19}$ have used this classification to correctly assess the definition and correlate interventions with wound healing index and limb salvage. In his study, Zhan included 201 patients, out of which 42 required major amputation (21\%) and 159 (78\%) preserved their extremity at one year; this group had a prevalence of more advanced disease in comparison with the limb salvage group (1:3).

As previously mentioned, few investigations have deeply examined the factors that influence on diabetic foot ulcer healing results at the moment of revascularization. ${ }^{20}$ In Mexico, this represents an extremely important problem due to the high prevalence of diabetes, although some authors have claimed that limb salvage is not necessarily linked to the need for revascularization. ${ }^{21}$ On the other hand, the European Society for Vascular Surgery recommends local debridement in the site of infection rather than a revascularization procedure. ${ }^{22}$ Similarly, the Trans-Atlantic Inter-Society Consensus (TASC) II for the management of peripheral artery disease, indicates that revascularization should be considered if there are clear signs of critical ischemia present or if healing doesn't occur in spite of optimal non-invasive treatment. ${ }^{8}$

Although there is still limited information on revascularization outcome in patients with diabetes and peripheral artery disease with an ulcer, and most studies that include patients with and without diabetes report an outcome in terms of limb salvage instead of ulcer healing. ${ }^{23}$ Faglia et al. ${ }^{24}$, with regard to early debridement and revascularization in patients with deep, acute infection, concluded that early revascularization had better results than mere clinical observation and intravenous antibiotic treatment.

The limitations we recognize in our investigation include its retrospective nature, a reduced number of patients and a negative potential for bias in the selection of those who underwent revascularization; about this issue, the decision to intervene was made by independent vascular surgeons. Balloon angioplasty was the first treatment choice if available, while open revascularization was performed in patients who were not candidate for angioplasty owing to clinical or economic reasons.

In conclusion, we observed that less than half the patients with advanced tissue loss according to PEDIS and Wagner classifications preserved the extremity in spite of revascularization. Early reference to vascular surgery department and implementation and evaluation of more appropriate selection criteria, such as the Wound, Ischemia and Foot Infection classification system, might increase limb salvage in this group of patients. The present study emphasizes on the need for research with regard to the selection of diabetic patients with ulcers who might benefit from open or endovascular revascularization with limb salvage purposes.

\section{Declaration of interests}

The authors declare not having any conflicts of interests.

\section{References}

1. Richard JL, Schuldiner S. Epidemiology of diabetic foot problems. Rev Med Int. 2008;29(Suppl 2):S222-S230.

2. Singh N, Armstrong DG, Lipsky BA. Preventing foot ulcers in patients with diabetes. JAMA. 2005;293(2):217-228.

3. Driver VR, Fabbi M, Lavery LA, Gibbons G. The cost of diabetic foot, the economic case for the limb salvage team. J Vasc Surg. 2010;52(3 Suppl):17S-22S

4. Lavery LA, Armstrong DG, Wunderlich RP, Mohler MJ, Wendel CS, Lipsky BA. Risk factors for foot infections in individuals with diabetes. Diabetes Care. 2006;29(6):1288-1293. 
5. Armstrong DG, Mills JL. Toward a change in syntax in diabetic foot care prevention, equals remission. J Am Podiatr Med Assoc. 2013;103(2): 161-162.

6. Armstrong DG, Wrobel J, Robbins JM. Guest editorial: are diabetes related wounds and amputations worse than cancer? Int Wound J. 2007; 4(4):286-287

7. Apelqvist J, Bakker K, Van-Houtum WH, Nabuurs-Franssen $M$ Schaper NC. International consensus and practical guidelines on the management and the prevention of the diabetic foot. International Working Group on the Diabetic Foot. Diabetes Metab Res Rev. 2000;16(Suppl 1):S84-92

8. Schaper NC, Apelvist J, Bakker K. Reducing lower leg amputation in diabetes: a challenge for patients healthcare providers and healthcare system. Diabetologia. 2012;55(7):1869-1872.

9. Armstrong DG, Lavery LA, Harkless LB. Validation of a diabetic wound classification system. The contributions of depth, infection, and ischemia to risk of amputation. Diabetes Care. 1998;21(5):855-859

10. Norgren L, Hiatt WR, Dormandy JA, Nehler MR, Harris KA, Fowkes FG. Inter-Society Consensus for the Management of Peripheral Arterial Disease (TASC II). J Vasc Surg. 2007;45(1 Suppl):S5-S67.

11. Eslami MH, Zayaruzny M, Fitzgerald GA. The adverse effects of race insurance status, and low income on the rate of amputation in patients presenting with lower extremity ischemia. J Vasc Surg. 2007; 45(1):55-59.

12. Alexandrescu V, Hubermont G, Philips Y, Guillaumie B, Ngongang C, Coessens V, et al. Combined primary subintimal and endoluminal angioplasty for ischaemic inferior limb ulcers in diabetic patients: 5-year practice in multidisciplinary diabetic foot service. Eur J Vasc Endovasc Surg 2009;37(4):448-456.

13. Castro G, Liceaga G, Arrioja A, Calleja JM, Espejel A, Flores J, et al Guía clínica basada en evidencia para el manejo del pie diabético. Med Int Mex. 2009;25(6):481-526.

14. Schaper NC. Diabetic foot ulcer classification system for research purposes: a progress report on criteria for including patients in research studies. Diabetes Metab Res Rev. 2004;20(Suppl 1):S90-S95.

15. Bell PRF, Charlesworthd D, DePalma RG, Eastcostt HHG, Eklof B, Jamieson CW, et al. The definition of critical ischemia of a limb. Working
Party of the International Vascular Symposium. Br J Surg. 1982; 69(Suppl 1):S2.

16. Apelquvist J, Elgzyri T, Larrson J, Löndahl M, Nyberg P, Thörne J. Factors related to outcome of neuroischemic/ischemic foot ulcer in diabetic patients. J Vasc Surg. 2011;53(6):1582-1588.

17. Wagner FW. The dysvascular foot: a system for diagnosis and treatment. Foot Ankle. 1981;2(2):64-122.

18. Mills JL Sr, Conte MS, Armstrong DG, Pomposelli FB, Schanzer A Sidawy AN, et al. The Society for Vascular Surgery Lower Extremity Threatened Limb Classification System: risk stratification based on wound, ischemia, and foot infection (WIfl). J Vasc Surg. 2014;59(1): 220-234.e1-2.

19. Zhan LX, Branco BC, Armstrong DG, Mills JL. The Society for Vascular Surgery lower extremity threatened limb classification system based on Wound, Ischemia, and foot Infection (WIfl) correlates with risk of major amputation and time to wound healing. J Vasc Surg. 2015;61(4): 939-944.

20. Elgzyri T, Larsson J, Nyberg P, Thörne J, Eriksson KF, Apelqvist J. Early revascularization after admittance to a diabetic foot center affects the healing probability of ischemic foot ulcer in patients with diabetes. See comment in PubMed Commons belowEur J Vasc Endovasc Surg. 2014:48(4):440-446

21. Cabeza-De-Vaca FG, Macias AE, Ramirez WA, Munoz JM, Alvarez JA Mosqueda JL, et al. Salvaging diabetic foot through debridement, pressure alleviation, metabolic control, and antibiotics. Wound Repair Regen. 2010;18(6):567-571.

22. Lepäntalo M, Apelqvist J, Setacci C, Ricco JB, De-Donato G, Becker F, et al. Chapter V: diabetic foot. Eur J Vasc Endovasc Surg. 2011;42(Suppl. 2):S60-S74.

23. Hinchliffe RJ, Andros G, Apelvist J, Bakker K, Friederich S, Lammer J, et al. A systemic review of the effectiveness of revascularization of the ulcerated foot in patients with diabetes and peripheral arterial disease. Diabetes Metab Res Rev. 2012;28(Suppl 1):179-217.

24. Faglia E, Clerici G, Caminiti M, Quaranteiello A, Gino M, Morabito A. The role of early surgical debridment and revascularization in patients with diabetes and deep foot space abscess: retrospective review of 106 patients with diabetes. J Foot Ankle Surg. 2006;45(4):220-226. 